\title{
Hubungan antara Waktu Tindakan Intubasi dengan Outcome Pasien Stroke di RSUP Prof. Dr. R. D. Kandou Manado: Kajian terhadap Glasgow Coma Scale, Ventilator Associated Pneumonia, Length of Stay, dan Angka Kematian
}

\author{
${ }^{1}$ Timothy M. Poluan \\ ${ }^{2}$ Diana Ch. Lalenoh \\ ${ }^{2}$ Barry I. Kambey
}

\author{
${ }^{1}$ Program Studi Pendidikan Dokter Fakultas Kedokteran Universitas Sam Ratulangi \\ ${ }^{2}$ Bagian Anestesiologi dan Terapi Intensif Fakultas Kedokteran Universitas Sam \\ Ratulangi/RSUP Prof. Dr. R. D. Kandou Manado \\ Email: timmypoluan@ymail.com
}

\begin{abstract}
Stroke patients with decreased consciousness, airway disorders, hypoxia, apnea or therapeutic initiation of hyperventilation must be intubated. The delay in intubation time in stroke patients with a deteriorating general condition is very dangerous because it is related to higher mortality within the first 24 to 48 hours and will affect the length of stay (LOS). One of the indications for intubation in stroke patients is the decrease in consciousness, namely the Glasgow Coma Scale (GCS) score <9. Albeit, intubation and mechanical ventilation can cause a person 6 to 21 times more likely to develop pneumonia, commonly referred to as ventilator associated pneumonia (VAP). This study was conducted at Prof. Dr. R. D. Kandou Hospital Manado and was aimed to obtain the correlation between time of intubation and stroke patient's outcome based on GCS, VAP, LOS, and mortality. The results showed that there was no relationship between time of intubation $<48$ hours or $\geq 48$ hours after stroke and improvement of GCS $(0 \%)$; between time of intubation $<48$ hours or $\geq 48$ hours after stroke and the occurence of VAP $(P=0.698)$; and between time of intubation $<48$ hours or $\geq 48$ hours after stroke and LOS $(\mathrm{r}=0.265 ; P=0.054)$; as well as between time of intubation $<48$ hours or $\geq 48$ hours after stroke and mortality in the first two days after intubation $(P=0.313)$.
\end{abstract}

Keywords: stroke, time of intubation, outcome.

\begin{abstract}
Abstrak: Pasien stroke dengan penurunan kesadaran, gangguan jalan napas, hipoksia, apnea atau inisiasi terapetik hiperventilasi harus diintubasi. Penundaan waktu tindakan intubasi pada pasien stroke dengan keadaan umum yang memburuk sangat berisiko karena berkaitan dengan mortalitas dalam waktu 24-48 jam pertama dan akan memengaruhi length of stay (LOS). Indikasi dilakukannya intubasi terhadap pasien stroke salah satunya ialah penurunan kesadaran yang dinilai dengan skor Glasgow Coma Scale (GCS) <9. Intubasi dan ventilasi mekanik dapat menyebabkan seseorang 6 sampai 21 kali lipat cenderung terkena pneumonia (ventilator associated pneumonia/VAP). Penelitian ini bertujuan untuk mendapatkan hubungan antara waktu tindakan intubasi dengan outcome pasien stroke di RSUP Prof. Dr. R. D. Kandou Manado dengan menggunakan kajian terhadap GCS, VAP, LOS, dan angka kematian. Hasil penelitian memperlihatkan tidak terdapat hubungan antara waktu tindakan intubasi <48 jam atau $\geq 48$ jam setelah serangan stroke dengan perbaikan GCS (0\%); dengan kejadian VAP $(P=0,698)$; dengan $\operatorname{LOS}(\mathrm{r}=0,265 ; P=0,054)$; dan dengan angka kematian pada 2 hari pertama setelah diintubasi $(P=0,313)$.
\end{abstract}

Kata kunci: stroke, waktu tindakan intubasi, outcome 
Stroke menempati urutan nomor 1 penyakit paling sering penyebab kematian di Indonesia pada tahun 2014 setelah jantung dan pembuluh darah di urutan kedua dan diabetes melitus serta komplikasinya di urutan ketiga. ${ }^{1}$ Pasien stroke dengan penurunan kesadaran, gangguan jalan napas, hipoksia, apnea, atau inisiasi terapetik hiperventilasi harus diintubasi. ${ }^{2}$ Gangguan jalan napas seperti adanya obstruksi jalan napas paling sering disebabkan karena adanya paralisis pada otot faring dan lidah sehingga menyebabkan apnea. Prognosis dari pasien-pasien stroke yang memerlukan intubasi endotrakeal dan ventilasi mekanik memiliki angka mortalitas yang tinggi yakni $49 \%-93 \% .^{2,3}$ Sekitar $15-20 \%$ pasien dengan stroke iskemik akut harus mendapatkan perawatan di intensive care unit (ICU). Pasien dengan stroke hemoragik harus memerlukan penanganan di ICU. $^{4}$ Beberapa penelitian menunjukkan angka mortalitas yang cukup tinggi dari pasien stroke yang diintubasi dan dirawat di ICU. Ludwigs et $\mathrm{al}^{5}$ melaporkan angka mortalitas sebesar $75 \%$. Burtin et $\mathrm{al}^{6}$ melaporkan bahawa 170 pasien stroke yang diintubasi memiliki angka mortalitas $72 \%$, Steiner, et $\mathrm{al}^{7}$ melaporkan angka mortalitas $52 \%$. Penelitian dari Gujjar et $\mathrm{al}^{8}$ melaporkan angka mortalitas $57 \%$ pada pasien stroke iskemik dan $58 \%$ pada pasien stroke hemoragik. Penundaan waktu tindakan intubasi pada pasien stroke dengan keadaan umum yang memburuk sangat berbahaya karena berkaitan dengan mortalitas dalam waktu 24-48 jam pertama. ${ }^{9}$ Pasien yang diintubasi $>48$ jam pertama mempunyai angka mortalitas yang lebih tinggi dibandingkan dengan yang diintubasi lebih cepat. Lama rawat inap atau length of stay (LOS) lebih panjang pada pasien yang diintubasi lebih dari $>48$ jam. $^{10}$ Indikasi dilakukannya intubasi terhadap pasien stroke salah satunya ialah faktor penurunan kesadaran yakni dengan skor Glasgow Coma Scale (GCS) <9. ${ }^{11}$

Intubasi dan ventilasi mekanik dapat menyebabkan seseorang 6-21 kali lipat cenderung terkena pneumonia yang disebut ventilator associated pneumonia (VAP). ${ }^{12}$
Hilker et al $^{13}$ melaporkan sekitar 82\% (14 dari 17 pasien) kejadian VAP pada pasien stroke dan Kwon et al $^{14}$ melaporkan sekitar 77\% kejadian VAP (24 dari 31 pasien).

Hasil pengambilan data awal yang dilakukan oleh peneliti di ruangan ICU RSUP Prof. Dr. R. D. Kandou Manado memperoleh hasil pada periode Januari 2015 hingga Desember 2017 terdapat sebanyak 83 pasien stroke yang dirawat di ICU dengan 38 pasien yang diintubasi.

Penelitian ini bertujuan untuk mendapatkan hubungan antara waktu tindakan intubasi dengan outcome pasien stroke di RSUP Prof. Dr. R. D. Kandou Manado dengan menggunakan kajian terhadap GCS, VAP, LOS, dan angka kematian.

\section{METODE PENELITIAN}

Jenis penelitian ini ialah analitik retrospektif menggunakan data rekam medis pasien yang dirawat di ruang rawat intensif (Intensive Care Unit/ICU) RSUP Prof. Dr. R. D. Kandou Manado periode Januari 2015 - Desember 2017. Sampel penelitian diperoleh dengan menggunakan metode total sampling yaitu seluruh berkas rekam medis pasien stroke yang diintubasi.

\section{HASIL PENELITIAN}

Berdasarkan pengumpulan data rekam medis yang dilakukan di Bagian Rekam Medis RSUP Prof. Dr. R. D. Kandou Manado periode Januari 2015 - Desember 2017, didapatkan 38 data pasien stroke yang diintubasi.

Subjek penelitian ini berjumlah 38 pasien stroke yang diintubasi sesuai dengan data rekam medis, terdiri dari 19 orang pasien laki-laki (50\%) dan 19 orang pasien perempuan $(50 \%)$.

Tabel 1 menunjukkan distribusi pasien stroke yang diintubasi berdasarkan usia. Yang terbanyak ialah pasien berusia 56-65 tahun $(36,8 \%)$, diikuti pasien berusia $>65$ tahun $(31,6 \%)$ dan pasien berusia $46-55$ tahun $(21,1 \%)$.

Tabel 2 memperlihatkan karakteristik subjek penelitian berdasarkan waktu tindakan intubasi. Didapatkan subjek yang terintubasi pada waktu <48 jam sebanyak 
14 pasien $(36,8 \%)$ dan $\geq 48$ jam sebanyak 24 pasien $(63,2 \%)$.

Tabel 1. Karakteristik subjek menurut usia

\begin{tabular}{cc}
\hline Usia (tahun) & Jumlah \\
\hline $26-35$ & $1(2,6 \%)$ \\
$36-45$ & $3(7,9 \%)$ \\
$46-55$ & $8(21,1 \%)$ \\
$56-65$ & $14(36,8 \%)$ \\
$>65$ & $12(31,6 \%)$ \\
Total & $38(100 \%)$ \\
\hline
\end{tabular}

Tabel 2. Waktu tindakan intubasi

\begin{tabular}{cc}
\hline $\begin{array}{c}\text { Waktu tindakan } \\
\text { intubasi }\end{array}$ & Jumlah \\
\hline$<48$ jam & $14(36,8 \%)$ \\
$\geq 48$ jam & $24(63,2 \%)$ \\
Total & $38(100 \%)$ \\
\hline
\end{tabular}

Tabel 3 menunjukkan bahwa pasien stroke yang diintubasi dengan positif ventilator associated pneumonia berjumlah 3 pasien $(7,9 \%)$ dan yang negatif VAP berjumlah $35(92,1 \%)$.

Tabel 3. Karakteristik subjek menurut kejadian VAP

\begin{tabular}{cc}
\hline VAP & Jumlah \\
\hline Positif & $3(7,9 \%)$ \\
Negatif & $35(92,1 \%)$ \\
Total & $38(100 \%)$ \\
\hline
\end{tabular}

Tabel 4 memperlihatkan karakteristik subjek penelitian menurut perbaikan GCS. Didapatkan bahwa semua pasien stroke yang terintubasi yakni berjumlah 38 pasien (100\%) tidak mengalami perbaikan GCS.

Tabel 4. Karakteristik subjek menurut GCS

\begin{tabular}{cc}
\hline Peningkatan GCS & Jumlah \\
\hline Positif & 0 \\
Negatif & $38(100 \%)$ \\
Total & $38(100 \%)$ \\
\hline
\end{tabular}

Tabel 5 menunjukkan karakteristik subjek penelitian berdasarkan angka kematian. Sebanyak 19 pasien (50\%) meninggal dalam waktu $\leq 2$ hari dan sebanyak 19 pasien $(50 \%)$ yang meninggal $>2$ hari.

Tabel 5. Karakteristik subjek menurut angka kematian

\begin{tabular}{cc}
\hline Angka kematian & Jumlah \\
\hline$\leq 2$ hari & $19(50 \%)$ \\
$>2$ hari & $19(50 \%)$ \\
Total & $38(100 \%)$ \\
\hline
\end{tabular}

Tabel 6 menunjukkan bahwa semua pasien stroke yang diintubasi $<48$ jam tidak mengalami peningkatan GCS dan juga semua pasien stroke yang diintubasi $\geq 48$ jam tidak mengalami peningkatan GCS.

Tabel 6. Waktu tindakan intubasi dengan GCS

\begin{tabular}{cccc}
\hline $\begin{array}{c}\text { Waktu } \\
\text { tindakan } \\
\text { intubasi }\end{array}$ & $\begin{array}{c}\text { GCS } \\
\text { Positif }\end{array}$ & $\begin{array}{c}\text { GCS } \\
\text { Negatif }\end{array}$ & Total \\
\hline$<48$ jam & 0 & 14 & 14 \\
& & $(100 \%)$ & $(100 \%)$ \\
$\geq 48$ jam & 0 & 24 & 24 \\
& & $(100 \%)$ & $(100 \%)$ \\
Total & 0 & 38 & 38 \\
& & $(100 \%)$ & $(100 \%)$ \\
\hline
\end{tabular}

Tabel 7 menunjukkan bahwa VAP pada pasien stroke yang diintubasi sebanyak 1 pasien VAP positif $(7,1 \%)$ dengan waktu tindakan intubasi $<48$ jam dan pada waktu tindakan intubasi $\geq 48$ jam terdapat 2 pasien VAP positif $(8,3 \%)$ dengan total 3 pasien VAP Positif $(7,9 \%)$ dan sebanyak 35 pasien tidak mengalami $\operatorname{VAP}(92,1 \%)$.

Hasil uji Fisher's Exact Test yang mendapatkan nilai $P=0,698(P>0,05)$ yang menunjukkan bahwa korelasi antara waktu tindakan intubasi dengan VAP tidak bermakna.

Tabel 8 menunjukkan hubungan antara waktu tindakan intubasi dengan LOS yang diuji dengan uji korelasi point biserial. Hasil uji ini mendapatkan nilai korelasi $\mathrm{r}=$ 0,265 dengan nilai $P=0,054(P>0,05)$ yang menyatakan terdapat hubungan yang lemah dan tidak bermakna antara waktu tindakan intubasi dengan LOS. 
Tabel 7. Hubungan waktu tindakan intubasi dengan VAP

\begin{tabular}{ccccc}
\hline $\begin{array}{c}\text { Waktu } \\
\text { tindakan } \\
\text { intubasi }\end{array}$ & $\begin{array}{c}\text { VAP } \\
\text { Positif }\end{array}$ & $\begin{array}{c}\text { VAP } \\
\text { Negatif }\end{array}$ & Jumlah & $\boldsymbol{P}$ \\
\hline$<48$ jam & 1 & 13 & 14 & \\
& $(7,1 \%)$ & $(92,9 \%)$ & $(100 \%)$ & \\
$\geq 48$ jam & 2 & 22 & 24 & \\
& $(8,3 \%)$ & $(91,7 \%)$ & $(100 \%)$ & \\
Total & 3 & 35 & 38 & 0,698 \\
& $(7,9 \%)$ & $(92,1 \%)$ & $(100 \%)$ & \\
\hline
\end{tabular}

Tabel 8 Hubungan waktu tindakan intubasi dengan LOS

\begin{tabular}{|c|c|c|c|}
\hline \multicolumn{2}{|c|}{ Variabel } & Korelasi & $P$ \\
\hline $\begin{array}{c}\text { Waktu } \\
\text { tindakan } \\
\text { intubasi }\end{array}$ & LOS & 0,265 & 0,054 \\
\hline
\end{tabular}

Tabel 10 menunjukkan bahwa angka kematian pasien stroke terintubasi $<48$ jam sebanyak 9 pasien $(64,3 \%)$ meninggal dalam waktu $\leq 2$ hari dan sebanyak 5 pasien $(35,7 \%)$ meninggal dalam waktu $>2$ hari. Angka Kematian pada pasien stroke terintubasi $\geq 48$ jam sebanyak 10 pasien $(41,7 \%)$ meninggal dalam waktu $\leq 2$ hari dan sebanyak 14 pasien $(58,3 \%)$ meninggal dalam waktu $>2$ hari. Total angka kematian $\leq 2$ hari sebanyak 19 pasien $(50 \%)$ dan $>2$ hari sebanyak 19 pasien (50\%).

Hasil uji Chi Square mendapatkan signifikansi 0,313 ( $P>0,05)$ yang menunjukkan bahwa tidak terdapat hubungan antara waktu tindakan intubasi dengan angka kematian.

Tabel 9. Hubungan waktu tindakan intubasi dengan angka kematian

\begin{tabular}{ccccc}
\hline Waktu tindakan intubasi & \multicolumn{2}{c}{ Angka kematian } & Jumlah & $\boldsymbol{P}$ \\
& $\leq 2$ hari & $>2$ hari & & \\
\hline$<48$ jam & $9(64,3 \%)$ & $5(35,7 \%)$ & $14(100 \%)$ & \\
$\geq 48$ jam & $10(41,7 \%)$ & $14(58,3 \%)$ & $24(100 \%)$ & \\
Total & $19(50, \%)$ & $19(50 \%)$ & $38(100 \%)$ & 0,313 \\
\hline
\end{tabular}

\section{BAHASAN}

Perlindungan jalan napas pada pasien stroke memerlukan intervensi yang harus segera dilakukan. Perburukan keadaan pasien stroke seperti adanya peningkatan tekanan intrakranial (TIK), gangguan di pusat respiratorik yakni apnea, paralisis otot faring dan lidah yang mengakibatkan obstruksi jalan napas, serta penurunan kesadaran merupakan indikasi-indikasi untuk diintubasi dan pemasangan ventilasi mekanik pada pasien stroke. ${ }^{11}$ Glasgow coma scale hanyalah salah satu indikasi dalam melakukan intubasi yakni dengan skor $<9 .{ }^{11}$

Pada penelitian ini didapatkan hasil pada Tabel 4 dan 6 menunjukkan bahwa semua pasien stroke (38 pasien) yang diintubasi tidak mengalami perbaikan GCS baik pada waktu tindakan intubasi $<48$ jam maupun waktu tindakan intubasi $\geq 48$ jam. Hasil tersebut tidak dapat diuji dengan uji analisis karena hanya terdapat 1 kategori saja yakni negatif. Dapat dikatakan bahwa lama atau cepatnya pasien menerima tindakan intubasi setelah serangan stroke tidak memengarui perbaikan dari tingkat kesadaran pasien itu sendiri.

Tingkat kesadaran pada pasien stroke dipengaruhi oleh faktor resiko yang ada. Beberapa penelitian mengemukakan bahwa faktor risiko dari gangguan kesadaran setelah serangan stroke ialah usia, jenis kelamin, stroke sebelumnya, atrial fibrilasi, diabetes melitus, alkohol, lokasi infark, serta keparahan dari stroke tersebut. ${ }^{15}$ Penilaian tingkat kesadaran dari pasienpasien tersebut dilakukan di ruang Intensive Care Unit maka karakteristik pasien di ICU seperti penggunaan obat-obat sedatif dan analgetik maupun penggunaan ventilator itu sendiri juga dapat memengaruhi tingkat atau penilaian kesadaran pasien. ${ }^{16}$

Menurut definisinya VAP adalah pneumonia yang muncul lebih dari 48 atau 72 jam setelah intubasi dimana saat 
tindakan intubasi tidak ada indikasi bahwa pneumonia sudah ada sebelumnya atau sedang berkembang. Intubasi dan ventilasi mekanik dapat menyebabkan seseorang 621 kali lipat cenderung terkena pneumonia. Pada Tabel 7 hanya terdapat 3 pasien $(7,9 \%)$ yang terbukti positif VAP dari total 38 pasien stroke yang diintubasi. Hal ini berbeda dengan penelitian yang dilakukan oleh Hilker et $\mathrm{al}^{13}$ yang melaporkan 14 kejadian VAP $(82 \%)$ dari 17 pasien stroke yang diintubasi serta Kwon et $\mathrm{al}^{14}$ melaporkan 24 dari 31 pasien (77\%). Kedua penelitian tersebut menunjukkan angka kejadian VAP pada pasien stroke yang diintubasi cukup tinggi. Pada penelitian yang dilakukan oleh Kasuya et al ${ }^{17}$ dilaporkan 31 pasien $(28 \%)$ dari 111 pasien stroke positif VAP yakni tergolong rendah dibandingkan dengan kedua penelitian tersebut. Kasuya et al $^{17}$ juga melaporkan bahwa pasien stroke yang positif VAP cenderung memiliki skor yang lebih tinggi pada NIHSS (tingkat keparahan stroke), keparahan kondisi pasien (APACHE II) dan Sequential Organ Failure Assessment (SOFA) dibanding dengan yang tidak terkena VAP.

Pada Tabel 7 sebanyak 1 pasien VAP positif dengan waktu intubasi lebih cepat ( $<48$ jam) dan 2 pasien VAP positif dengan waktu intubasi lebih lama ( $\geq 48$ jam). Pembuktian adanya korelasi antara waktu tindakan intubasi dengan kejadian VAP pada pasien stroke diuji menggunakan $C h i$ Square/Fisher Exact yang menunjukkan hasil analisis korelasi antara tindakan intubasi cepat ataupun lambat yakni $<48$ jam atau $\geq 48$ jam setelah serangan stroke dengan kejadian VAP dinyatakan tidak terdapat hubungan bermakna $(P=0,698)$.

Length of stay (LOS) atau lama hari rawat menunjukkan berapa hari lamanya seorang pasien dirawat inap pada satu periode perawatan. Satuan untuk LOS ialah hari dan dalam penelitian ini dihitung sejak pasien masuk dari ICU. Terjadi perpanjangan LOS (prolonged length of stay) di ICU adalah ketika seorang pasien dirawat sekurangnya 14 hari semenjak dimasukan ke ICU. Perpanjangan LOS akan mening- katkan pembiayaan dan kebutuhan perawatan rumah sakit dan juga akan menambah beban dari keluarga pasien. ${ }^{18}$

Hasil penelitian yang dilakukan oleh Tobi dan Frederick ${ }^{19}$ menunjukkan bahwa sebanyak 49 pasien yang terpasang ventilator mekanik dari total 175 pasien yang dirawat ICU terjadi perpanjangan LOS pada 27 pasien $(30 \%)$ sedangkan 22 pasien $(24,4 \%)$ tidak mengalami perpanjangan LOS. Penelitian oleh Bauer et $\mathrm{al}^{10}$ mengenai waktu tindakan intubasi terhadap pasien-pasien di ICU menunjukkan bahwa pasien yang diintubasi lebih lambat akan lebih cenderung meningkatkan LOS di ICU maupun LOS di rumah sakit dibanding dengan pasien yang lebih cepat diintubasi.

Berdasarkan Tabel 8 dengan mengesampingkan kategori adanya perpanjangan LOS atau tidak menunjukkan bahwa hubungan antara waktu tindakan intubasi dengan LOS yang diuji dengan korelasi point biserial mendapatkan nilai korelasi $\mathrm{r}=0,265$ dengan nilai $P=0,054$. Hasil tersebut menyatakan terdapat hubungan yang lemah dan tidak bermakna antara waktu tindakan intubasi semenjak serangan stroke dan LOS $(P>0,05)$.

Tabel 5 dan 9 menunjukkan bahwa terdapat 19 pasien $(50 \%)$ yang meninggal pada $\leq 2$ hari pertama dan 19 pasien $(50 \%)$ meninggal $>2$ hari setelah dilakukan intubasi dari total 38 pasien $(100 \%)$ yang diintubasi dan meninggal. Penelitian ini sejalan dengan penelitian-penelitian sebelumnya oleh Ludwigs et al $^{5}$ yang melaporkan angka mortalitas setinggi 75\%; Burtin et $\mathrm{al}^{6}$ melaporkan dari 170 pasien stroke yang diintubasi terdapat angka mortalitas $72 \%$; Steiner et $\mathrm{al}^{7}$ melaporkan angka mortalitas $52 \%$, serta Gujjar et al $^{8}$ melaporkan angka mortalitas $57 \%$ pada pasien stroke iskemik dan $58 \%$ pada pasien stroke hemoragik. Semua penelitian ini menunjukkan angka kematian yang cukup tinggi yakni lebih dari 50\%.

Penundaan waktu untuk tindakan intobasi pada pasien stroke yang mengalami perburukan berkaitan erat dengan kematian pada 24-48 jam pertama. $^{9}$ Tindakan intubasi yang dilakukan lebih lama yakni 
$>48$ jam akan memiliki risiko kematian lebih besar dibandingkan dengan tindakan intubasi lebih cepat yakni $<48$ jam. $^{10}$ Waktu tindakan intubasi yang dilakukan setelah serangan stroke dalam penelitian ini menunjukkan bahwa berdasarkan hasil uji korelasi antara waktu tindakan intubasi tersebut (cepat $<48$ jam dan lambat $\geq 48$ jam) dengan angka kematian $\leq 2$ hari dan $>2$ hari (Tabel 9) diperoleh hasil $P=0,313$ $(P>0,05)$ yang menunjukkan tidak terdapat hubungan bermakna antara waktu tindakan intubasi cepat atau lambat sejak serangan dengan angka kematian pada 2 hari pertama setelah tindakan.

\section{SIMPULAN}

Berdasarkan hasil penelitian ini dapat disimpulkan bahwa pada pasien stroke yang dirawat di ICU RSUP Prof. Dr. R. D. Kandou Manado tidak terdapat hubungan antara waktu tindakan intubasi $<48$ jam atau $\geq 48$ jam setelah serangan stroke dengan perbaikan GCS maupun antara waktu tindakan intubasi $<48$ jam atau $\geq 48$ jam setelah serangan stroke dengan kejadian VAP, antara waktu tindakan intubasi $<48$ jam atau $\geq 48$ jam setelah serangan stroke dengan LOS, dan antara waktu tindakan intubasi $<48$ jam atau $\geq 48$ jam setelah serangan stroke dengan angka kematian pada 2 hari pertama setelah diintubasi.

\section{SARAN}

Diharapkan pada penelitian lanjut digunakan periode waktu yang lebih panjang untuk mendapatkan sampel lebih banyak. Selain itu untuk penelitian lanjut diharapkan meneliti hubungan waktu tindakan intubasi dan outcome pasien stroke dengan jenis stroke yang lebih spesifiik.

\section{DAFTAR PUSTAKA}

1. Dirjen Pencegahan dan Pengendalian Penyakit Kemenkes RI. Kebijakan dan Strategi Pencegahan dan Pengendalian Stroke di Indonesia. Jakarta: Kemenkes RI, 2018.

2. Bushnell CD, Phillips-Bute BG, Laskowitz DT, Lynch JR, Chilukuri V, Borel CO. Survival and outcome after endotracheal intubation for acute stroke. Neurology. 1999;52(7):1374.

3. Mayer SA, Copeland D, Bernardini GL, Boden-Albala B, Lennihan $\mathrm{L}$, Kossoff S, et al. Cost and outcome of mechanical ventilation for lifethreatening stroke. Stroke. 2000;31: 2346-53.

4. Perioperative management of hemorrhagic stroke. Bagian Anestesiologi \& Terapi Intensif Fakultas Kedokteran Universitas Padjadjaran RS. Dr. Hasan Sadikin-Bandung

5. Ludwigs UG, Baehrendtz S, Wanecek M, Matell G. Mechanical ventilation in medical and neurological diseases: 11 years of experience. Intern Med J. 1991;229:117-24.

6. Burtin P, Bollaert PE, Feldmann L, Nace L, Lelarge P, Bauer P, et al. Prognosis of stroke patients undergoing mechanical ventilation. Intensive Care Medicine 1994;20:32-6.

7. Steiner T, Mendoza G, Georgia MD, Schellinger P, Holle R, Hacke W. Prognosis of Stroke Patients Requiring Mechanical Ventilation in a Neurological Critical Care Unit. Stroke. 1997;28:711-5.

8. Gujjar AR, Deibert E, Manno EM, Duff S, Diringer MN. Mechanical ventilation for ischemic stroke and intracerebral hemorrhage: Indications, timing, and outcome. Neurology. 1998;51:447-51.

9. Grotta J, Pasteur W, Khwaja G, Hamel T, Fisher M, Ramirez A. Elective intubation for neurologic deterioration after stroke. Neurology 1995;45:640-4.

10. Bauer PR, Gajic O, Nanchal R, Kashyap R, Martin-Loeches I, Sakr Y, et al. Association between timing of intubation and outcome in critically ill patients: A secondary analysis of the ICON audit. J Crit Care. 2017;42:1-5.

11. Abdul G. Manajemen Stroke. Yogyakarta: Pustaka Cendekia Press, 2009.

12. Mehndiratta M, Nayak R, Ali S, Sharma A, Gulati N. Ventilators in ICU: a boon or burden. Annals of Indian Academy of Neurology. 2016;19:69.

13. Hilker R, Poetter C, Findeisen N, Sobesky $J$, Jacobs A, Neveling $M$, et al. Nosocomial pneumonia after acute stroke: implications for neurological intensive care medicine. Stroke 2003; 
34:975-81.

14. Kwon H-M, Jeong S-W, Lee S-H, Yoon BW. The pneumonia score: A simple grading scale for prediction of pneumonia after acute stroke. Am J Infect Control. 2006;34:64-8.

15. Li J, Wang D, Tao W, Dong W, Zhang J, Yang $\mathbf{J}$, et al. Early consciousness disorder in acute ischemic stroke: incidence, risk factors and outcome. BMC Neurology 2016;16. doi:10.1186/ s12883-016-0666-4.

16. Oktarina Y, Simajuntak CA. Perbandingan Glasgow coma scale dengan full outline of unresponsiveness score dalam mengukur tingkat kesadaran pasien terintubasi endotracheal tube di
Intensive Care Unit. Seminar Nasional Keperawatan 2017 Dec 20 (Vol. 1, No. 1, pp. 50-54).

17. Kasuya Y, Hargett J, Lenhardt R, Heine M, Doufas A, Remmel K, et al. J Crit Care. 2011;26(3):273-9.

18. Zampieri FG, Colombar F, Deb LC, Santoro C, Haib D. Factors associated with prolonged stay in the Intensive Care Unit: A retrospective analysis. Crit Care Med. 2013;17:1186.

19. Tobi KU, Amadasun FE. Prolonged stay in the Intensive Care Unit of a tertiary hospital in Nigeria: Predisposing factors and outcome. Afr J Med Health Sci. 2015;14:56-60. 